\title{
High Molecular Weight Gingipains from Porphyromonas gingivalis Induce Cytokine Responses from Human Macrophage-Like Cells via a Nonproteolytic Mechanism
}

\author{
Rebecca E. Fitzpatrick ${ }^{a, b} \quad$ Andrea Aprico ${ }^{a, b} \quad$ Lakshmi C. Wijeyewickrema $^{a, b}$ \\ Charles N. Pagelc David M. Wong ${ }^{a, c}$ Jan Potempa ${ }^{d}$ Eleanor J. Mackie ${ }^{c}$ \\ Robert N. Pike ${ }^{a, b}$ \\ ${ }^{a}$ Cooperative Research Centre for Oral Health Sciences and bepartment of Biochemistry and Molecular Biology, \\ Monash University, Clayton, Vic., and 'School of Veterinary Science, University of Melbourne, Parkville, Vic., \\ Australia; ${ }^{\mathrm{d} D e p a r t m e n t}$ of Microbiology, Faculty of Biochemistry, Biophysics and Biotechnology, \\ Jagiellonian University, Krakow, Poland
}

\section{Key Words}

Porphyromonas gingivalis · Gingipains • Protease ·

Macrophages $\cdot$ Cytokines $\cdot$ Periodontal disease

\begin{abstract}
Periodontal disease is an oral inflammatory disease affecting the supporting structures of teeth. Porphyromonas gingivalis, a major pathogenic agent for the disease, expresses a number of virulence factors, including cysteine proteases called the gingipains. The arginine- and lysine-specific gingipains, HRgpA and Kgp, respectively, are expressed as high molecular weight forms containing both catalytic and adhesin subunits. We examined the expression pattern of cytokines and their receptors in differentiated macrophages following exposure to active and inactive forms of the gingipains, using a CDNA array, quantitative PCR and ELISA analysis. Amongst other pro-inflammatory cytokines, results from the cDNA array suggested that interleukin-1 $\beta$, granulocyte-macrophage colony stimulatory factor and interferon- $\gamma$ were upregulated after exposure of the macrophages to the gingipains. Quantitative PCR analysis substantiated these observations and indicated that active or
\end{abstract}

inactive forms of the high molecular weight gingipains were able to upregulate expression of transcripts for these cytokines. The strongly enhanced production of interleukin- $1 \beta$ and granulocyte-macrophage colony stimulatory factor by differentiated macrophages in response to active or inactive forms of the high molecular weight gingipains was confirmed at the protein level by ELISA analysis. The results indicate that the adhesin subunits of the gingipains mediate strong upregulation of the expression of pro-inflammatory cytokines in macrophages. Copyright $\odot 2008 \mathrm{~S}$. Karger AG, Basel

\section{Introduction}

Periodontal disease is an oral disorder characterized by inflammation of the gingiva and the supporting structures of the periodontium [1], most likely as a consequence of a complex immunopathological host response to microbial challenge. This may eventually result in destruction of the periodontal tissues, alveolar bone resorption around the tooth root surface and, ultimately, exfoliation of the teeth [2]. More than 300 different species of

\section{KARGER}

Fax +4161306 1234

E-Mail karger@karger.ch

www.karger.com
(C) 2008 S. Karger AG, Basel

1662-811X/09/0012-0109\$26.00/0

Accessible online at:

www.karger.com/jin
Dr. Robert N. Pike

Department of Biochemistry and Molecular Biology

Monash University, Clayton, Vic. 3800 (Australia)

Tel. +61 39905 3923, Fax +61 399054699

E-Mail rob.pike@med.monash.edu.au 
bacteria have been identified as members of the periodontal environment [1] and homeostasis in the healthy periodontium is maintained by a complex multifactorial process involving interactions between multiple bacterial species, their products, many of which are immunomodulating, and host cells. This balance can be disturbed by colonization of dental biofilm by predominantly Gramnegative, anaerobic bacteria considered to be periodontopathogenic, with Porphyromonas gingivalis deemed to be one of the most important [3]. Interaction of these bacteria with the host is ultimately pathogenic, with the host cell releasing cytokines and enzymes capable of destroying the host periodontal tissue and producing conditions of chronic inflammation in the gingiva and periodontium $[1,4]$.

P. gingivalis is a nonmotile, Gram-negative, obligate anaerobe that has been implicated as a major causative agent in the development and progression of chronic periodontitis [5-9]. The bacterium has a number of important virulence factors, including the cysteine proteases (gingipains), which have been particularly implicated as a causal link in the progression of periodontitis [1015]. P. gingivalis produces 2 arginine-specific cysteine proteases, RgpA and RgpB, and 1 lysine-specific cysteine protease, Kgp. RgpA and Kgp proteases contain a catalytic domain with a C-terminal Ig-like subdomain (IgSF) and 4 hemagglutinin/adhesin subunits [16], while RgpB consists of only the catalytic domain and a small C-terminal segment [16] implicated in a novel pathway of gingipain secretion [17].

The gingipains have been implicated in a wide variety of pathogenic activities in the host [18] and interact with host cells to cause a number of responses that may be associated with disease. The arginine-specific gingipains have been found to activate protease-activated receptors on epithelial cells [19] and platelets [20], with the former causing the upregulation of interleukin (IL)- 6 production by the cells. Protease-activated receptor-2 (PAR-2) appears to play a significant role in the progression of periodontal disease, since PAR-2 null mice are apparently protected against periodontal disease [21]. The gingipains have been demonstrated to up-regulate production of a number of cytokines and other pro-inflammatory genes from monocytes [22], monocyte-epithelial cell cocultures [23] and stromal cells or osteoblasts [24]. The perturbation of the cytokine signaling networks and proinflammatory genes are 2 mechanisms through which $P$. gingivalis may be able to initiate tissue destruction and alveolar bone resorption in the host.
Under conditions of chronic inflammation, such as in periodontal disease, the mononuclear phagocyte or macrophage is one of the principle cell types involved in the inflammatory response against infection. The exact role that macrophages play in periodontitis has not been fully elucidated, but it is known that exposure to $P$. gingivalis and components such as lipopolysaccharides (LPS) or fimbriae induces the expression of pro-inflammatory cytokines [25-28]. The aim of this study was to determine whether any of these responses could be attributed to the gingipains. We have examined the responses of differentiated macrophage-like cells to the gingipains of $P$. gingivalis and show that there is marked upregulation of expression of IL-1 $\beta$ in particular, but that this expression is induced independently of the proteolytic activity of the gingipains.

\section{Materials and Methods}

\section{Materials}

The human monocytic cell line THP-1 was purchased from the ATCC (Rockville, Md., USA). Fetal bovine serum, L-glutamine, penicillin, phorbol 12-myristate 13-acetate (PMA), ProPhe-Arg-chloromethylketone, nonenzymatic dissociation solution, heat-denatured sheared salmon testes DNA and streptomycin sulfate were purchased from Sigma-Aldrich (Sydney, N.S.W., Australia). All primers for polymerase chain reaction (PCR) and quantitative PCR (qPCR) were synthesized by Geneworks (Adelaide, S.A., Australia). Reverse transcription PCR (RT-PCR) reagents, were purchased from Promega (Madison, Wisc., USA). The RNeasy mini kit was purchased from Qiagen (Hilden, Germany), RPMI 1640, SuperScript III reverse transcriptase, Platinum ${ }^{\circledR}$ SYBR $^{\circledR}$ Green qPCR SuperMix, SYBR Safe reagent and Sybr Green master mix were purchased from Invitrogen (Carlsbad, Calif., USA). Pyrotell ${ }^{\circledR}$ Limulus Amebocyte Lysate gel clot test was purchased from Associates of Cape Cod Inc. (East Falmouth, Mass., USA). The human cytokine/receptor Atlas nylon cDNA expression array, AtlasImage 2.01 software and ExpressHyb were purchased from Clontech (BD Biosciences, San Jose, Calif., USA). $\alpha-{ }^{33} \mathrm{P}$ dATP was purchased from Amersham Biosciences (Little Chalfont, UK). Micro Bio Spin columns were purchased from BioRad (Hercules, Calif., USA). The Quantikine ${ }^{\circledR}$ human granulocyte-macrophage colony stimulatory factor (GM-CSF) ELISA kit was obtained from R\&D Systems (Minneapolis, Minn., USA). The human IL-1 $\beta$ ReadySETGo! and human interferon- $\gamma$ (IFN- $\gamma$ ) ReadySETGo! ELISA kits were obtained from eBioscience (San Diego, Calif., USA). Human PAR-1 activating peptide (PAR-1 A/P; TFFLR) and human PAR-2 activating peptide (PAR-2 A/P: SLIGRL) were synthesized as carboxyamide derivatives and purified by high-performance liquid chromatography to $>95 \%$ purity by AusPep (Melbourne, Vic., Australia).

Tissue Culture Conditions and Differentiation of THP-1 Cells

The human monocytic cell line, THP-1, was maintained in RPMI 1640 medium, supplemented with 10\% heat-inactivated fe- 
tal bovine serum, $2 \mathrm{mM}$ L-glutamine, penicillin $\mathrm{G}(100 \mathrm{U} / \mathrm{ml})$ and streptomycin sulfate $(100 \mu \mathrm{g} / \mathrm{ml})$ in $5 \% \mathrm{CO}_{2}$ at $37^{\circ} \mathrm{C}$. For microarray and qPCR experiments, THP-1 cells were seeded at a density of $1 \times 10^{7}$ cells/flask in $75-\mathrm{cm}^{2}$ flasks, grown until they reached a density of $1 \times 10^{6}$ cells $/ \mathrm{ml}$, washed twice in phosphatebuffered saline (PBS) and treated with $10 \mathrm{nM}$ PMA for $48 \mathrm{~h}$ in $5 \%$ $\mathrm{CO}_{2}$ at $37^{\circ} \mathrm{C}$ to induce differentiation into macrophage-like adherent cells. For ELISA experiments, THP-1 cells were seeded at a density of $2 \times 10^{6}$ cells/well and were differentiated as described above in 6-well tissue culture plates (Techno Plastic Products, Zurich, Switzerland).

\section{Purification and Activation of the Gingipains}

The enzymes RgpB, HRgpA and Kgp were purified from culture supernatants of $P$. gingivalis strain HG66 as previously described $[29,30]$. The gingipains were activated with $10 \mathrm{mM}$ cysteine at $37^{\circ} \mathrm{C}$ for $10 \mathrm{~min}$ in $0.2 \mathrm{M}$ Tris- $\mathrm{HCl}, 0.1 \mathrm{M} \mathrm{NaCl}$ and $5 \mathrm{mM}$ $\mathrm{CaCl}_{2}, \mathrm{pH} 7.6$ and, when necessary, inactivated by incubating with $100 \mu \mathrm{M}$ Pro-Phe-Arg-chloromethylketone at $37^{\circ} \mathrm{C}$ for 20 $\min$.

\section{RNA Isolation and Synthesis of cDNA}

For microarray and qPCR experiments, after PMA treatment the cells were washed twice in PBS, incubated overnight in serumfree RPMI media, then challenged with $2.5 \mathrm{nM}$ active HRgpA, 2.5 $\mathrm{nM}$ inactive HRgpA and $2.5 \mathrm{nM}$ active $\mathrm{Kgp}$ for $1 \mathrm{~h}$ at $37^{\circ} \mathrm{C}$ in $5 \%$ $\mathrm{CO}_{2}$ (conditions that had been used in a previous study of cytokine responses in epithelial cells without any adverse effects on the cells [31]). For the microarray experiments, immediately after the 1-hour treatment, the THP-1 cells were washed twice in PBS and incubated with nonenzymatic dissociation solution at $37^{\circ} \mathrm{C}$ in $5 \% \mathrm{CO}_{2}$ for $5 \mathrm{~min}$ to detach the cells from the flask. After detachment, the cells were lysed and the RNA was immediately extracted using the RNeasy mini kit according to the manufacturer's instructions. For the qPCR experiments, after treatment for $1 \mathrm{~h}$, the cells were washed twice in PBS and then either the RNA was extracted immediately as described above or the cells were incubated in serum-free RPMI media with the RNA subsequently extracted 3, 12 or $24 \mathrm{~h}$ after the initial incubation period. The quality and quantity of purified RNA was checked by agarose gel electrophoresis and UV spectroscopy at 260 and $280 \mathrm{~nm}$. RNA samples with a ratio of A260/A280 $\geq 2.0$ and without degradation as analyzed by agarose gel electrophoresis were used for microarray assays and $\mathrm{qPCR}$ experiments. All samples were stored at $-80^{\circ} \mathrm{C}$ until required. Reverse transcription was conducted with $1 \mu \mathrm{g}$ of total cellular RNA using SuperScript III reverse transcriptase $(200 \mathrm{U} / \mu \mathrm{l})$ for first-strand cDNA synthesis in a $20-\mu \mathrm{l}$ reaction volume in accordance with the manufacturer's instructions. The synthesized cDNA was subsequently used as a template in qPCR experiments.

\section{Quantitative Real-Time PCR}

To determine the relative levels of expression of specific cytokines expressed in differentiated THP-1 cells treated with $2.5 \mathrm{nM}$ active HRgpA, $2.5 \mathrm{nM}$ inactive HRgpA or $2.5 \mathrm{nM}$ active Kgp, qPCR was performed using a Corbett Real-Time PCR Rotorgene 3,000 machine (Corbett Research, Sydney, N.S.W., Australia). Forward and reverse oligonucleotide primer pairs (online supplementary table 1; for supplementary material see www.karger.com/doi/000181145) were designed specifically for
qPCR using the web-based software program Primer3 [32] and designed to overlap exon-exon boundaries to ensure specific amplification of mRNA transcripts. qPCR reactions were optimized for each primer pair by varying concentrations of primer and cDNA. For each gene of interest and the housekeeping gene glyceraldehyde 3-phosphate dehydrogenase (GAPDH), qPCR assays were performed on 3 biological samples, in triplicate. Cycling was performed using $10 \mu \mathrm{l}$ Platinum ${ }^{\circledR}$ SYBR $^{\circledR}$ Green qPCR SuperMix, $500 \mathrm{nM}$ of each forward and reverse primer and $1 \mu \mathrm{l}$ cDNA template, using the following cycle profile: $55^{\circ} \mathrm{C}$ for $2 \mathrm{~min}, 95^{\circ} \mathrm{C}$ for $2 \mathrm{~min}$, followed by 40 cycles consisting of $95^{\circ} \mathrm{C}$ for $30 \mathrm{~s}, 55^{\circ} \mathrm{C}$ for $30 \mathrm{~s}$ and $72^{\circ} \mathrm{C}$ for $30 \mathrm{~s}$, followed by a thermal melt profile from 60 to $95^{\circ} \mathrm{C}$. Fluorescence readings were detected at the end of each extension step using the FAM/SYBR channel of the machine. Upon completion of cycling, a melt curve of fluorescence versus temperature was generated to ensure that a single amplicon was obtained for each primer set. Following amplification, cycle threshold values for housekeeping genes and genes of interest were exported to Microsoft Excel. Relative expression of each gene of interest in treated samples, expressed relative to untreated samples and normalized to the housekeeping gene, along with statistical analysis using the nonparametric randomization reallocation test and determination of the standard error for treatments was performed using the relative expression software tool (REST) [33].

\section{ELISA Analysis and Cell Normalization}

For ELISA experiments, after PMA treatment the cells were washed twice with PBS and challenged with 2, 20 or $200 \mathrm{nM}$ active or inactive HRgpA, Kgp or RgpB, $100 \mu \mathrm{M}$ PAR-1 AP or $100 \mu \mathrm{M}$ PAR-2 AP for 18 or $36 \mathrm{~h}$ at $37^{\circ} \mathrm{C}$ in $5 \% \mathrm{CO}_{2}$. The conditioned culture medium was harvested, centrifuged at $150 \mathrm{~g}$ for $5 \mathrm{~min}$ and the supernatant was aliquoted and stored at $-20^{\circ} \mathrm{C}$ until required. After collection of the culture supernatant, cells were lysed in 500 $\mu l 0.1 \mathrm{M}$ Tris- $\mathrm{HCl}, \mathrm{pH} 8$, containing $0.5 \%$ (v/v) Triton X-100 and the DNA content was measured as described previously [34] using the SYBR Safe reagent. DNA content was found to be essentially constant across all conditions tested and therefore results were not normalized to this parameter.

GM-CSF, IL-1 $\beta$ or IFN- $\gamma$ released by THP-1 cells, when challenged by the gingipains or peptide agonists, were detected using sandwich ELISAs. GM-CSF released by THP-1 was detected using the Quantikine ${ }^{\circledR}$ human GM-CSF ELISA kit in accordance with the manufacturer's instructions. The GM-CSF ELISA plates, precoated with murine monoclonal antibodies against recombinant human GM-CSF, were incubated with $100 \mu$ l serially diluted recombinant human GM-CSF standards or conditioned media at room temperature for $2 \mathrm{~h}$. Bound GM-CSF was detected using $200 \mu \mathrm{l}$ antihuman GM-CSF antibody conjugated to horseradish peroxidase. The concentrations of GM-CSF in the samples were calculated from the linear range of the standard curve.

IL- $1 \beta$ or IFN- $\gamma$ released by THP-1 cells were detected using the human IL-1 $\beta$ ReadySETGo! and the human IFN $\gamma$ ReadySETGo! ELISA kits, respectively, in accordance with the manufacturer's instructions. The ELISA plates, precoated with monoclonal antibodies raised against recombinant human IL-1 $\beta$ (clone CRM56) or recombinant human IFN- $\gamma$ (clone NIB42) were incubated with $100 \mu$ l serially diluted recombinant human IL-1 $\beta /$ IFN- $\gamma$ standards or conditioned media overnight at $4^{\circ} \mathrm{C}$. After washing, $100 \mu \mathrm{l} /$ well of biotin-conjugated detection antibody was 
added, incubated at room temperature for $1 \mathrm{~h}$, following which $100 \mu \mathrm{l} /$ well of avidin-horseradish peroxidase conjugate was added and incubated at room temperature for $30 \mathrm{~min}$. Detection was carried out using tetramethylbenzidine substrate solution which was read at $450 \mathrm{~nm}$ using a BioRad 3550 microplate reader. The concentrations of IL- $1 \beta / \mathrm{IFN}-\gamma$ in the samples were calculated from the linear range of the standard curve.

Limulus Amebocyte Lysate Test

To detect and quantify the presence of Gram-negative bacterial endotoxin (LPS) contamination of the purified RgpA, RgpB or Kgp samples, the Pyrotell Limulus amebocyte lysate gel clot test was undertaken in accordance with the manufacturer's instructions. In brief, a series of endotoxin standards were prepared and tested to confirm the sensitivity of the Pyrotell reagent to be 0.03 endotoxin units $/ \mathrm{ml}$. Subsequently, 2 -fold serial dilutions (ranging from $2.5 \mathrm{nM}$ to $78.125 \mathrm{pM}$ ) of heat-inactivated Kgp, RgpB or HRgpA were prepared and $200 \mu$ l of each dilution was added to single test vials of Pyrotell which contained $200 \mu \mathrm{l}$ of lyophilized Limulus amebocyte lysate. Tubes were incubated at $37^{\circ} \mathrm{C}$ for $1 \mathrm{~h}$. After the incubation period, if a gel clot had formed in the vials and remained intact after the vials were inverted by $180^{\circ}$, the sample was deemed positive for LPS contamination. No detectable amount of LPS contamination was seen for any of the gingipain preparations.

\section{Results and Discussion}

Previously, we have shown that activation of PARs by arginine-specific gingipains causes cytokine responses in oral epithelial cells [19] and therefore our null hypothesis at the outset of this study was that effects of the gingipains on the macrophages would most likely be mediated via the PARs. With this in mind, active and inactive forms of the high molecular weight arginine-specific gingipain, HRgpA, were used to reveal the differences between responses most likely due to PAR-mediated effects (from active HRgpA) and those mediated by other effects (from inactive HRgpA). The human cytokine/receptor Atlas nylon cDNA expression array was used as an initial screen to examine cytokine/receptor expression in THP-1 cells when challenged with $2.5 \mathrm{nM}$ active or inactive HRgpA or $2.5 \mathrm{nM}$ active Kgp (for experimental details, see online supplementary Materials and Methods). The concentrations of enzymes used were based on previous experience with epithelial cells, where only small concentrations of the enzymes were tolerated by the cells without adverse effects such as lifting of the cells [19], although later in the study it was established that the differentiated THP-1 cells were resistant to much higher concentrations of enzyme without lifting of the cells from the surface occurring. Similarly, a time point of $1 \mathrm{~h}$ was used based on previous experiences, with RNA isolated immediately after exposure to the gingipains. The effect of time on expressed genes was investigated later using qPCR analysis. We showed that the enzyme preparations were essentially free of LPS using a Limulus amebocyte lysate assay and that essentially no response was seen compared to boiled controls (data not shown). Each microarray analysis was performed twice using 2 biological samples for each treatment and the genes that were at least 2 -fold differentially expressed across both microarrays are listed in online supplementary tables 2-4.

Relative to untreated controls, differentiated THP-1 cells challenged with active HRgpA for $1 \mathrm{~h}$ showed upregulation ( $\geq 2$-fold HRgpA/control ratio) of the expression of 9 cytokine/cytokine receptor genes (3.4\%) of the 268 genes spotted onto the array (online supplementary table 2). These genes included $I L-4$ receptor (IL-4R; $\alpha$ subunit), IFN- $\gamma, I F N-\gamma$ receptor (IFN- $\gamma R$ ), IFN regulatory factor 1 (IRF1), CDW40 antigen, TRK-T3 oncoprotein, fibroblast growth factor 8 (FGF8) and epidermal growth factor $(E G F)$. The most highly upregulated gene was $I F N-\gamma$, which was upregulated 7.7-fold.

Inactive HRgpA challenge of differentiated THP-1 cells induced the upregulation of 27 (10.1\%) of the 268 cytokine/receptor genes (online supplementary table 3). Significantly upregulated genes included $I L-1 \beta, I L-10$, IFN- $\gamma$ antagonist, IFN- $\gamma R, I R F 1, B$ cell growth factor 1 precursor (BCGF1), GM-CSF, macrophage inflammatory protein $1 \alpha$ precursor $(M I P-1 \alpha)$, macrophage colony stimulating factor 1 receptor (MCSF-1R) and TNF- $\alpha$. The most highly upregulated gene was IFN- $\alpha / \beta R \beta$-subunit, which was upregulated 172 -fold. IFN- $\gamma R$, IRF1, CDW40 antigen and TRK-T3 oncoprotein were upregulated by both active and inactive HRgpA, implying that the proteolytic activity of HRgpA was not required for the induction of expression of these genes.

Challenge of the differentiated THP-1 cells with active Kgp for $1 \mathrm{~h}$ resulted in upregulation of 15 (5.6\%) of the 268 cytokine/receptor genes (online supplementary table 4). Upregulated genes included $I L-1 R 1, I L-4 R$ ( $\alpha$-subunit), IL-6R ( $\alpha$-subunit), IRF1 and BCGF1. The most highly upregulated gene was $I L-1 R 1$, which was upregulated 185 -fold. Interestingly, IRF1 was upregulated by all 3 treatment conditions. Cumulatively, the initial screen using the cytokine gene array indicated that $I L-1 \beta, I F N-\gamma$, $G M-C S F, I L-10$ and $I R F 1$ were interesting candidate genes to be investigated further using $\mathrm{qPCR}$.

The greater number of genes upregulated by the inactive form of HRgpA on the array (29 genes) than the active form (8 genes) and the higher level of the increase 


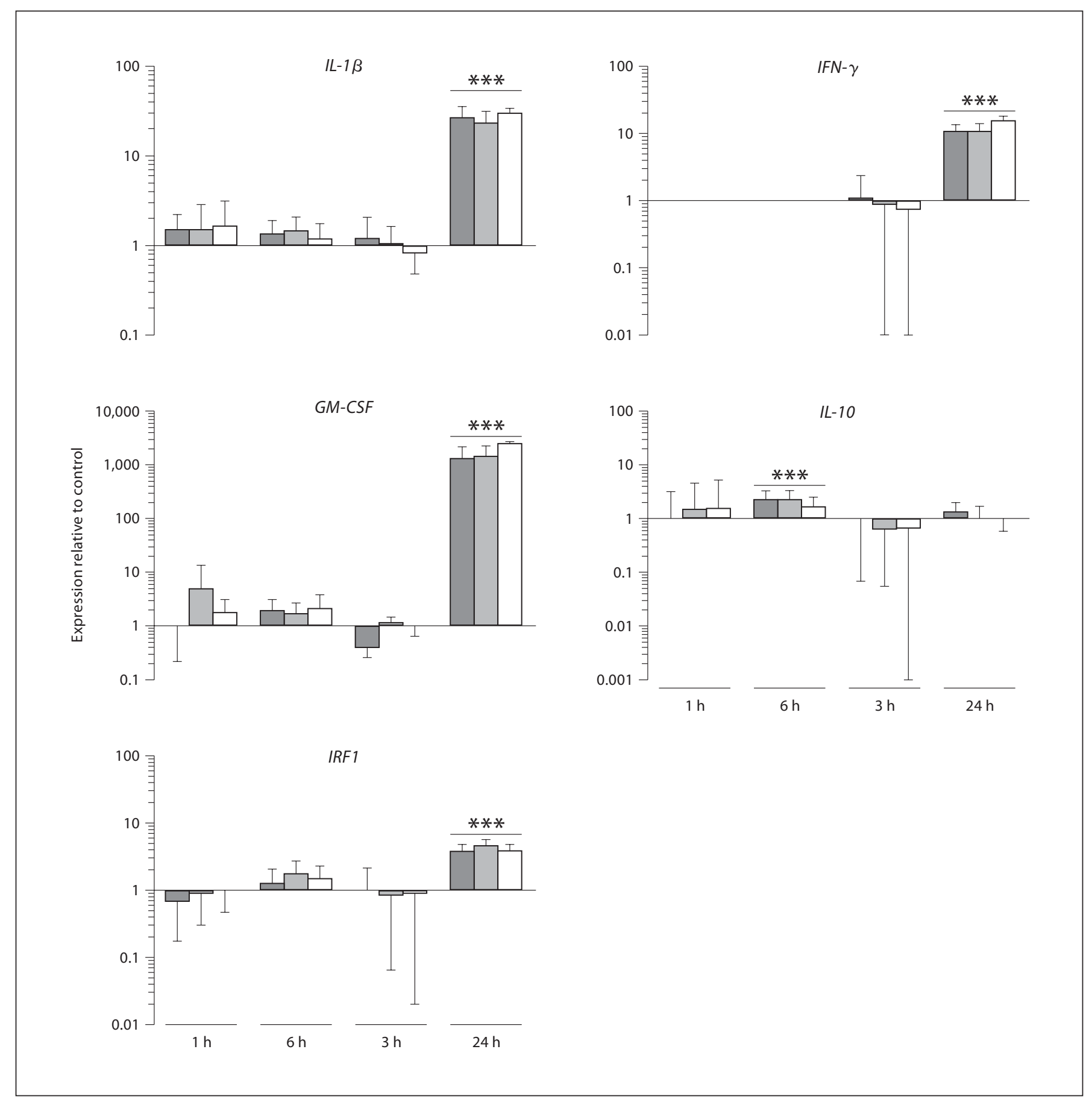

Fig. 1. Analysis of $I L-1 \beta, I F N-\gamma, G M-C S F, I L-10$ and $I R F 1$ expression in THP-1 cells in response to stimulation with $2.5 \mathrm{nM}$ active HRgpA (dark bars), $2.5 \mathrm{nM}$ inactive HRgpA (grey bars) or $2.5 \mathrm{nM}$ active Kgp (clear bars) for $1 \mathrm{~h}$. cDNA synthesized from RNA extracted immediately $(1 \mathrm{~h})$ or 3,6 or $24 \mathrm{~h}$ later from THP-1 cells challenged with each treatment was used as a template for $\mathrm{qPCR}$ reactions using $I L-1 \beta, I F N-\gamma, G M-C S F, I L-10, I R F 1$ and $G A P D H$

primers. The cycle threshold values were used to calculate $I L-1 \beta$, IFN- $\gamma$, GM-CSF, IL-10 and IRF1 transcript levels in treated cultures normalized to GAPDH relative to the normalized level of the transcripts for the same molecules in untreated samples. Data are presented as means $\pm \operatorname{SEM}(\mathrm{n}=3) .{ }^{* * *} \mathrm{p} \leq 0.001$. Comparisons between 2 groups were made by unpaired Student's t tests. 

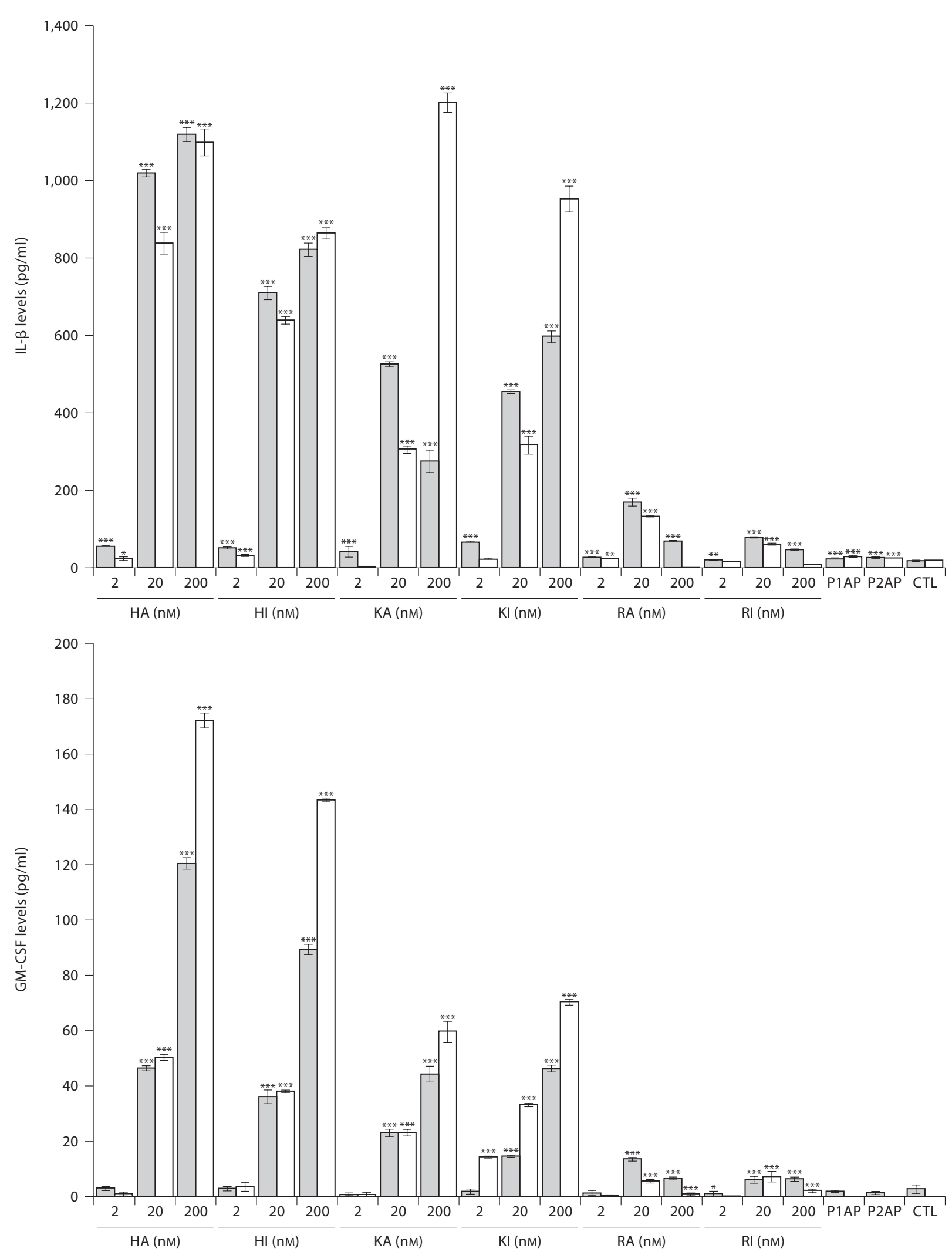
with inactive HRgpA (several genes above 5-fold enhancement in expression, only 1 above 5 for active HRgpA) was surprising given our null hypothesis of PAR involvement. Interestingly, more genes were commonly regulated by inactive HRgpA and active Kgp (7 genes) than were commonly regulated by active and inactive forms of HRgpA (3 genes), suggesting that the adhesin domains of HRgpA and Kgp, which have 90\% similarity, were mediating much of the response generated in cells. The inactive HRgpA and Kgp induced a similarly large upregulation of IRFI (over 100-fold in each case). Overall, most cytokines and their receptors upregulated by the gingipains would be considered pro-inflammatory, suggesting that the interaction of the bacterial enzymes with macrophages would promote a strong pro-inflammatory response from these cells.

In order to further investigate and validate the responses from the cytokine array, the responses of 4 genes noted to be upregulated in the array experiment $(I L-1 \beta$, $I F N-\gamma, G M-C S F$ and IRF-1) were further investigated using $\mathrm{qPCR}$. The expression of an anti-inflammatory gene, $I L-10$, was also investigated to provide further insight into the balance between pro- and anti-inflammatory responses of the macrophages in response to the gingipains. The relative levels of expression of these genes in differentiated THP-1 cells over time when treated with active and inactive forms of the gingipains are shown in figure 1. THP-1 cells were treated with $2.5 \mathrm{nM}$ active or inactive HRgpA, or $2.5 \mathrm{nM}$ active Kgp for $1 \mathrm{~h}$ and the RNA was extracted either immediately or 3,12 or $24 \mathrm{~h}$ after the initial incubation period. The pro-inflammatory cytokine genes $I L-1 \beta$ and $I F N-\gamma$ were significantly upregulated in THP-1 cells $24 \mathrm{~h}$ after being treated with active or inactive HRgpA, or active Kgp for $1 \mathrm{~h}$. Active HRgpA upregulated the expression of $I L-1 \beta$ by 27 -fold, inactive HRgpA upregulated the expression of $I L-1 \beta 23$-fold, while stimulation with active Kgp resulted in the 30 -fold upregulation of $I L-1 \beta$. IFN- $\gamma$ was less strongly upregulated by the gingipains: challenge with active or inactive

Fig. 2. IL-1 $\beta$ and GM-CSF secretion in THP-1 cells stimulated with 2-200 nM active HRgpA (HA), inactive HRgpA (HI), active Kgp (KA), inactive Kgp (KI), active RgpB (RA), inactive RgpB (RI), $100 \mu \mathrm{M}$ PAR-1 AP (P1AP) or $100 \mu \mathrm{M}$ PAR-2 AP (P2AP), compared to a control (CTL). The conditioned medium was recovered at $18 \mathrm{~h}$ (dark bars) or $36 \mathrm{~h}$ (light bars) and analyzed for levels of IL-1 $\beta$ and GM-CSF and compared to controls. Data are presented as means $\pm \operatorname{SEM}(\mathrm{n}=3) .{ }^{*} \mathrm{p} \leq 0.05 ;{ }^{*} \mathrm{p} \leq 0.01$; $* * * \mathrm{p} \leq 0.001$. Comparisons between 2 groups were made by unpaired Student's t tests.

Macrophage Cytokine Responses to Gingipains
HRgpA induced a 10.7-fold increase in the expression of IFN- $\gamma$ by THP- 1 cells $24 \mathrm{~h}$ after initial challenge, while active Kgp induced a 15-fold upregulation in the expression of IFN- $\gamma$ after $24 \mathrm{~h}$. The expression of GM-CSF was very powerfully and significantly upregulated in THP-1 cells $24 \mathrm{~h}$ after being treated with the active or inactive forms of the gingipains for $1 \mathrm{~h}$. Active and inactive HRgpA induced an upregulation in GM-CSF expression in differentiated THP-1 cells of 1,291- and 1,432-fold, respectively, while active Kgp induced a 2,475-fold upregulation in this gene. The anti-inflammatory cytokine $I L-10$ gene was significantly upregulated by treatment with active (2.3-fold) or inactive HRgpA (2.3-fold) $3 \mathrm{~h}$ after the initial incubation period. IRF1 was upregulated in THP-1 cells $24 \mathrm{~h}$ after stimulation with active or inactive HRgpA or active Kgp for $1 \mathrm{~h}$. Treatment with active HRgpA or Kgp upregulated the expression of IRF1 3.8-fold in THP1 cells, whereas treatment with inactive HRgpA upregulated the expression of IRF1 4.6-fold. It is possible that the difference in timing required to see upregulation of the gene expression using qPCR compared to the array data relates to the different sensitivities of the techniques employed. These results indicated that pro-inflammatory cytokine genes were upregulated by all forms of the gingipains, including inactive HRgpA, once again suggesting that the adhesin domains common between HRgpA and Kgp might be mediating the majority of the interactions leading to the response in the cells. The results also suggested that the pro-inflammatory genes were upregulated late in the macrophages following exposure to the gingipains.

To verify the upregulation in expression of $I L-1 \beta, I F N-$ $\gamma$ and GM-CSF gene products in differentiated THP-1 cells when challenged with active or inactive forms of the gingipains, ELISA analysis was undertaken. THP-1 cells were stimulated with 2, 20 or $200 \mathrm{nM}$ active or inactive HRgpA, active or inactive Kgp or active or inactive RgpB in comparison to $100 \mu \mathrm{M}$ PAR-1 AP or $100 \mu \mathrm{M}$ PAR-2 AP; the conditioned medium was recovered at 18 or $36 \mathrm{~h}$, following which the levels of IL-1 $\beta$, IFN- $\gamma$ and GM-CSF protein in each treatment condition were analyzed by ELISA (fig. 2). The ELISA analysis was carried out with higher concentrations of the gingipains, since initial results did not yield marked regulation of the protein levels using the low concentrations of the gingipains utilized in the gene expression analyses. This might simply reflect the different sensitivities of the techniques involved.

GM-CSF protein levels were strongly upregulated at the protein level by 20 or $200 \mathrm{nM}$ active/inactive HRgpA or Kgp, with active HRgpA prompting the highest re-

J Innate Immun 2009;1:109-117 
sponse, closely followed by the inactive form of the enzyme. Use of a low molecular weight form of the arginine-specific gingipain, RgpB, which lacks the adhesin subunits, but is a reasonably potent activator of PAR-2 at the levels used, gave rise to small responses in GM-CSF relative to the high molecular weight forms of the enzymes, indicating again the importance of the adhesin subunits of the enzymes in mediating the effects of the gingipains on macrophages. Additionally, agonist peptides for PAR-1 and PAR-2 were found to yield much lower responses for GM-CSF, indicating that the PARs were not playing a major role in mediating the responses to the gingipains in differentiated macrophages. Interestingly, a recent paper has shown that in the undifferentiated form of the monocytic cell line being used here, PARs played a major role in the generation of the IL-8 response prompted by exposure to the gingipains [22]. This suggests that the undifferentiated versus differentiated forms of these cells apparently respond quite differently to the gingipains. It should be noted here that RT-PCR analysis revealed that PAR-1, PAR-2 and PAR-3 were expressed by the differentiated THP-1 cells [Fitzpatrick et al., unpubl. results] and therefore should have been available to contribute to the responses to the arginine-specific gingipains. Indeed, it is likely that the difference in the response between active and inactive HRgpA might be attributable to PAR activation, as might be the responses to RgpB.

IL-1 $\beta$ levels were strongly upregulated following exposure to either of the high molecular weight gingipain forms, HRgpA and Kgp. This cytokine is seen as an early responder in inflammatory situations, with subsequent response of cells including the upregulation of the receptor for the IL, which was seen in the array analysis presented here, and subsequent release of many other cytokines [35]. This has previously been characterized to occur for oral epithelial cells in response to $P$. gingivalis or its products [35] and thus it is of interest to note here that the gingipains were also able to upregulate this pivotal cytokine. Once again, the predominant response of the cells appears to be mediated via the adhesin subunits of HRgpA and Kgp, with only minor contributions occurring via the activity of the enzymes.

The conditioned media from THP-1 cells treated with all activators for 18 or $36 \mathrm{~h}$ did not contain detectable amounts of IFN- $\gamma$ (data not shown). This result, contradictory to the gene expression analysis, might reflect the different sensitivity once again, as IFN- $\gamma$ was a gene that yielded a response on a very late cycle in the qPCR, indicating that very small quantities of the mRNA for the gene were present. This might indicate that while the gene was indeed upregulated in its expression, the actual levels of protein were in reality very low.

The profile of cytokine responses induced by the gingipains appears to indicate that these enzymes induce the majority of their response from differentiated macrophages through their adhesin subunits. At this stage, the receptors for these adhesin subunits on cells are generally not well characterized. It is conceivable that the adhesin subunits might be interacting with the TLR that are found on the surface of the differentiated macrophages, but this has never been shown. The fimbriae and LPS of P. gingivalis have been shown to bind TLR-2 and TLR-7 as well as to induce cytokine responses in macrophages [33] and therefore it would appear likely that the adhesin subunits of the gingipains may act to further augment such responses. The molecular targets of the gingipains on the surface of the cells remain to be characterized, but it seems clear that antagonizing such interactions might be one potential avenue to prevent pro-inflammatory responses from tissue macrophages which might mediate much of the unwanted chronic pro-inflammatory responses found in oral tissues following infection with $P$. gingivalis.

\section{References}

1 Holt SC, Kesavaku L, Walker S, Genco CA: Virulence factors of Porphyromonas gingivalis. Periodontol 2000 1999;20:168-238.

2 Schenkein H: The pathogenesis of periodontal diseases. J Periodontol 1999;70:457-470.

3 Lamont RJ, Jenkinson HF: Life below the gum line: pathogenic mechanisms of Porphyromonas gingivalis. Microbiol Mol Biol Rev 1998;62:1244-1263.
4 Dennison DK, Van Dyke TE: The acute inflammatory response and the role of phagocytic cells in periodontal health and disease. Periodontol 2000, 1997;14:54-78.

5 Slots J, Ting M: Actinobacillus actinomycetemcomitans and Porphyromonas gingivalis in human periodontal disease: occurrence and treatment. Periodontol 2000, 1999;20: 82-121.
6 Griffen AL, Becker MR, Lyons SR, Moeschberger ML, Leys EJ: Prevalence of Porphyromonas gingivalis and periodontal health status. J Clin Microbiol 1998;36:3239-3242.

7 Slots J, Listgarten MA: Bacteriodes gingivalis, Bacteriodes intermedius and Actinobacillus actinomycetemcomitans in human periodontal diseases. J Clin Periodontol 1988;15: 85-93. 
8 Holt SC, Ebersole J, Felton J, Brunsvold M, Kornman KS: Implantation of Bacteroides gingivalis in non-human primates initiates progression of periodontitis. Science 1988; 239:55-57.

9 Evans RT, Klausen B, Ramamurthy NS, Golub LM, Sfintescu C, Genco RJ: Periodontopathic potential of two strains of Porphyromonas gingivalis in gnotobiotic rats. Arch Oral Biol 1992;37:813-819.

10 Nakayama K, Kadowaki T, Okamoto K, Yamamoto K: Construction and characterization of arginine-specific cysteine proteinase (Arg-gingipain)-deficient mutants of Porphyromonas gingivalis. J Biol Chem 1995; 270:23619-23626.

11 Shi Y, Ratnayake DB, Okamoto K, Abe N, Yamamoto K, Nakayama K: Genetic analyses of proteolysis, hemoglobin-binding, and hemagglutination of Porphyromonas gingivalis: construction of mutants with a combination of $\operatorname{rgpA}, \operatorname{rgpB}, \mathrm{kgp}$ and $h a g A$. J Biol Chem 1999;274:17955-17960.

12 Tokuda M, Karunakaran T, Duncan M Hamada N, Kuramitsu H: Role of Arg-gingipain in virulence of Porphyromonas gingivalis. Infect Immun 1998;66:1159-1166.

13 Fletcher HM, Schenkein HA, Morgan RM, Bailey KA, Berry CR, Macrina FL: Virulence of a Porphyromonas gingivalis W83 mutant defective in the prtH gene. Infect Immun 1995; 63:1521-1528.

14 Grenier D, Roy S, Chandad F, Plamondon P, Yoshioka M, Nakayama K, Mayrand D: Effect of Inactivation of the Arg- and/or Lysgingipain gene on selected virulence and physiological properties of Porphyromonas gingivalis. Infect Immun 2003;71:47424748 .

15 O'Brien-Simpson NM, Paolini RA, Hoffmann B, Slakeski N, Dashper SG, Reynolds EC: Role of RgpA, RgpB, and Kgp proteinases in virulence of Porphyromonas gingivalis W50 in a murine lesion model. Infect Immun 2001;69:7527-7534.

16 Potempa J, Sroka A, Imamura T, Travis J: Gingipains, the major cysteine proteinases and virulence factors of Porphyromonas gingivalis: structure, function and assembly of multidomain protein complexes. Curr Prot Pep Sci 2003;4:397-407.
17 Nguyen KA, Travis J, Potempa J: Does the importance of the $\mathrm{C}$-terminal residues in the maturation of RgpB from Porphyromonas gingivalis reveal a novel mechanism for protein export in a subgroup of Gram-negative bacteria? J Bacteriol 2007;189:833-843.

18 Imamura T, Travis J, Potempa J: The biphasic virulence activities of gingipains: activation and inactivation of host proteins. Curr Prot Pep Sci 2003;4:443-450.

19 Lourbakos A, Potempa J, Travis J, D’Andrea MR, Andrade-Gordon P, Santulli R, Mackie EJ, Pike RN: Arginine-specific protease from Porphyromonas gingivalis activates protease-activated receptors on human oral epithelial cells and induces interleukin- 6 secretion. Infect Immun 2001;69:5121-5130.

20 Lourbakos A, Yuan Y, Jenkins AL, Travis J, Andrade-Gordon P, Santulli R, Potempa J, Pike RN: Activation of protease-activated receptors by gingipains from Porphyromonas gingivalis leads to platelet aggregation: a new trait in microbial pathogenicity. Blood 2001; 97:3790-3797.

21 Holzhausen M, Spolidorio LC, Ellen RP, Jobin MC, Steinhoff M, Andrade-Gordon $\mathrm{P}$, Vergnolle N: Protease-activated receptor-2 activation: a major role in the pathogenesis of Porphyromonas gingivalis infection. Am J Pathol 2006;168:1189-1199.

22 Uehara A, Imamura T, Potempa J, Travis J, Takada H: Gingipains from Porphyromonas gingivalis synergistically induce the production of proinflammatory cytokines through protease-activated receptors with Toll-like receptor and NOD1/2 ligands in human monocytic cells. Cell Microbiol 2008; 10: 1181-1189.

23 Bodet C, Chandad F, Grenier D: Modulation of cytokine production by Porphyromonas gingivalis in a macrophage and epithelial cell co-culture model. Microbes Infect 2005;7: 448-456.

24 Ohno T, Okahashi N, Kawai S, Kato T, Inaba H, Shibata Y, Morisaki I, Abiko Y, Amano A: Proinflammatory gene expression in mouse ST2 cell line in response to infection by Porphyromonas gingivalis. Microbes Infect 2006;8:1025-1034.

25 Amano A: Molecular interaction of Porphyromonas gingivalis with host cells: implication for the microbial pathogonesis of periodontal disease. J Periodontal 2003;74: 90-96.
26 Zhou Q, Desta T, Fenton M, Graves DT, Amar S: Cytokine profiling of macrophages exposed to Porphyromonas gingivalis, its lipopolysaccharide, or its FimA protein. Infect Immun 2005;73:935-943.

27 Saba JA, McComb ME, Potts DL, Costello CE, Amar S: Proteomic mapping of stimulus-specific signalling pathways involved in THP-1 cells exposed to Porphyromonas gingivalis or its purified components. J Proteome Res 2007;2211-2221.

28 Zhou Q, Amar S: Identification of signalling pathways in macrophage exposed to Porphyromonas gingivalis or to its purified cell wall components. J Immunol 2007; 179:77777790.

29 Chen Z, Potempa J, Polanowski A, Wikstrom $\mathrm{M}$, Travis J: Purification and characterization of a $50-\mathrm{kDa}$ cysteine proteinase (gingipain) from Porphyromonas gingivalis. J Biol Chem 1992;267:18896-18901.

30 Pike R, McGraw W, Potempa J, Travis J: Lysine- and arginine-specific proteinases from Porphyromonas gingivalis: isolation, characterization, and evidence for the existence of complexes with hemagglutinins. J Biol Chem 1994;269:406-411.

31 Lourbakos A, Potempa J, Travis J, D’Andrea MR, Andrade-Gordon P, Santulli R, Mackie EJ, Pike RN: Arginine-specific protease from Porphyromonas gingivalis activates protease-activated receptors on human oral epithelial cells and induces interleukin- 6 secretion. Infect Immun 2001;69:5121-5130.

- 32 Rozen S, Skaletsky H: Primer3 on the WWW for general users and for biologist programmers. Meth Mol Biol 2000;132:365-386.

-33 Pfaffl MW, Horgan GW, Dempfle L: Relative expression software tool (REST) for groupwise comparison and statistical analysis of relative expression results in real-time PCR. Nucleic Acids Res 2002;30:e36.

34 Uaesoontrachoon K, Yoo H-J, Tudor EM, Pike RN, Mackie EJ, Pagel CN: Osteopontin and skeletal muscle myoblasts: association with muscle regeneration and regulation of myoblast function in vitro. Int $\mathrm{J}$ Biochem Cell Biol 2008;40:2303-2314.

35 Eskan MA, Benakanakere MR, Rose BG, Zhang P, Zhao J, Stathopoulou P, Fujioka D, Kinane DF: Interleukin-1 $\beta$ modulates proinflammatory cytokine production in human epithelial cells. Infect Immun 2008;76:2080 2089. 